\title{
The potential of high-resolution BAC-FISH in banana breeding
}

\author{
Guy De Capdeville · Manoel Teixeira Souza Júnior • \\ Dóra Szinay • Leandro Eugênio Cardamone Diniz • \\ Erik Wijnker · Rony Swennen • \\ Gerrit Haatje Jan Kema · Hans De Jong
}

Received: 29 July 2008/Accepted: 30 September 2008/Published online: 19 October 2008

(C) The Author(s) 2008. This article is published with open access at Springerlink.com

\begin{abstract}
The genetic complexity in the genus Musa has been subject of study in many breeding programs worldwide. Parthenocarpy, female sterility, polyploidy in different cultivars and limited amount of genetic and genomic information make the production of new banana cultivars difficult and time consuming. In addition, it is known that part of the cultivars and related wild species in the genus contain numerous chromosomal rearrangements. In order to produce new cultivars more effectively breeders must better understand the genetic differences of the potential crossing parents for introgression hybridization, but extensive genetic information is lacking.
\end{abstract}

G. De Capdeville

Embrapa Recursos Genéticos e Biotecnologia,

Caixa Postal 02372,

Brasilia, DF CEP 70770-900, Brazil

G. De Capdeville

Universidade Católica de Brasília, Campus II,

SGAN Quadra 916, Módulo B, Av. W5 Norte, Brasilia,

DF CEP 70790-160, Brazil

\section{T. Souza Júnior}

Embrapa Labex Europe, Plant Research International B.V., Wageningen University and Research Centre, Droevendaalsesteeg 1, 6700 AA Wageningen,

The Netherlands

D. Szinay $\cdot$ E. Wijnker $\cdot$ H. De Jong $(\bowtie)$

Laboratory of Genetics, Wageningen University and

Research Centre, Arboretumlaan 4,
As an alternative to achieve information on genetic collinearity we make use of modern chromosome map technology known as high-resolution fluorescent in situ hybridization (FISH). This article presents the technical aspects and applications of such a technology in Musa species. The technique deals with BAC clone positioning on pachytene chromosomes of Calcutta 4 (Musa acuminata ssp. burmanicoides, A genome group, section Eumusa) and M. velutina (section Rodochlamys). Pollen mother cells digestion with pectolytic enzymes and maceration with acetic acid were optimized for making cell spread preparations appropriate for FISH. As an example of this

6703 BD Wageningen, The Netherlands

e-mail: Hans.dejong@wur.nl

L. E. C. Diniz

Embrapa Tabuleiros Costeiros, Caixa Postal 44, Aracaju, SE CEP 49025-040, Brazil

R. Swennen

Faculty of Bioscience Engineering Division of Crop Biotechnics, Laboratory of Tropical Crop Improvement, K.U. Leuven, Kasteelpark Arenberg 13 bus 2455, 3001 Leuven, Belgium

G. H. J. Kema

Plant Research International, Wageningen University and Research Centre, Droevendaalsesteeg 1, 6700 AA Wageningen, The Netherlands 
approach we chose BAC clones that contain markers to known resistance genes and hybridize them for establishing their relative positions on the two species. Technical challenges for adapting existing protocols to the banana cells are presented. We also discuss how this technique can be instrumental for validating collinearity between potential crossing parents and how the method can be helpful in future mapping initiatives, and how this method allows identification of chromosomal rearrangements between related Musa species and cultivars.

Keywords Musa acuminata $\cdot$ Musa velutina .

BAC-FISH · Chromosome mapping ·

Banana

$\begin{array}{ll}\text { Abbreviations } \\ \text { FISH } & \text { Fluorescent in situ hybridization } \\ \text { BAC } & \text { Bacterial artificial chromosome } \\ \text { FITC } & \text { Fluorescein isothiocyanate } \\ \text { DEAC } & \text { Diethylaminocoumarin } \\ \text { Cy3 } & \text { Cyanine } 3 \text { fluorochrome } \\ \text { Cy3.5 } & \text { Cyanine 3.5 fluorochrome }\end{array}$

\section{Introduction}

Bananas and plantains are among the most appreciated tropical fruits worldwide and rank fourth as staple food in most tropical countries. Its importance is not only due to commercial aspects, but has also social impacts, as many small growers are involved with its production (Food and Agriculture Organization 2004). Notwithstanding its economical importance little is known about the genetics, genomics and biotechnology of this crop (Pillay et al. 2004; Heslop-Harrison and Scharzacher 2007).

For more than 50 years researchers have been trying to understand the diversity of Musa based on morphological features and chromosome counts (Cheesman 1948; Simmonds and Shepherd 1955; Sharrock 1989; Tezenas du Montcel 1989; Shepherd 1999). Only recently studies appeared addressing the complexity of the banana genome using molecular and cytogenetic tools (Doležel et al. 1994, 1997; Osuji et al. 1997; D'Hont et al. 2000; Aert et al. 2004; Pillay et al. 2004; Bartoš et al. 2005; Heslop-Harrison and Scharzacher 2007; Ohl et al. 2007; Thomas-Hall et al. 2007). Such tools may in the long term be helpful in establishing breeding programs if more information on the genetic constitutions of the crossing partners becomes available.

Bananas (Musa spp.) belong to the family Musaceae and include 25 species, which have been divided into the Australimusa, Callimusa, Rhodochlamys, and Eumusa sections (Simmonds and Shepherd 1955). Geographically the Eumusa section is the most widespread and contains two major species, Musa acuminata (A genome) and Musa balbisiana (B genome), which are used for inter- and intraspecific crosses for the production of commercial cultivars. Although the A- and B- bananas have the same chromosome number $(2 n=22)$ in their cell complement, their genome size, as estimated by flow cytometry, differ between 10 and $15 \%$ with an average genome size for $M$. balbisiana of $537 \mathrm{Mbp}$ and for M. acuminata genome sizes ranging from 591 to 615 Mbp (Doležel et al. 1994; Lysák et al. 1999; Kamaté et al. 2001; Bartoš et al. 2005).

The diploid $M$. acuminata and $M$. balbisiana bananas have been the basis for many breeding programs around the world, in which the former contributes parthenocarpy and major fruit quality traits, while the latter provides hardiness (Šafár et al. 2004). Parthenocarpy and female sterility in $M$. acuminata result in seedless fruits. Most hybrids obtained by crossing M. acuminata and M. balbisiana have inherited these parthenocarpy and sterility traits (Heslop-Harrison and Scharzacher 2007), which make conventional cross breeding to obtain commercial cultivars with resistance to different biotic and abiotic stresses difficult and time consuming (HeslopHarrison and Scharzacher 2007). Consequently, breeders have to exploit a wide range of fertile banana varieties as a source of genes in order to set up successful banana breeding programs. For example, Musa species from the Rhodochlamys section including Musa velutina and M. laterita are potentially interesting for their drought tolerance (Häkkinen 2007).

In recent studies molecular markers were identified for banana classification (Wong et al. 2002; Buhariwalla et al. 2005; Santos et al. 2005; Ruangsuttapha et al. 2007; Swangpol et al. 2007; Miller et al. 2008), but the usefulness of these markers depends on (a) the distribution pattern of the markers on the chromosomes; (b) the genetic and structural location of these markers on conserved regions of 
different genomes; and (c) the possibility of chromosomal rearrangements between potential crossing parents in the chromosome regions of economically important traits (Pillay et al. 2004). In order to determine small chromosomal rearrangements such as translocations and inversions or even the position of a smaller DNA sequence a more refined methodology based on single copy fluorescent in situ hybridization (FISH) is required. Furthermore, the potential of FISH for studying the banana genome has increased considerably after the construction of a number of BAC libraries from M. acuminata and from M. balbisiana (Vilarinhos et al. 2003; Šafár et al. 2004). From those libraries a number of molecular markers have been identified and sequenced (Santos et al. 2005; Miller et al. 2008), but their chromosomal positions have not yet been established. In addition, at least one molecular marker based linkage group map has been constructed (Fauré et al. 1993).

Cytogenetic methods came at hand to map BACs and other sequences directly on the chromosomes. Initially it focused only on the FISH detection of rDNA sequences and few BAC clones on the tiny mitotic chromosomes (Osuji et al. 1997; Doleželova et al. 1998; D'Hont 2005), a method which is not appropriate for detailed cytogenetic analysis. The alternative for mitotic complements as chromosomal targets is the use of the long and well-differentiated pachytene chromosomes in FISH. Pachytene chromosomes in plants are not only $10-50 \times$ longer than mitotic metaphase chromosomes, and thus allow a higher degree of spatial resolution, but also display a clear differentiation of heterochromatin blocks, which helps the identification of individual chromosomes, rearrangements and translocations, and establishes repeat-rich domains (de Jong et al. 1999). There is only one study on spreading pachytene complements of Musa (Adeleke et al. 2002), which include cell wall digestion and cell spreading of pollen mother cells. However, the use of Ferric Chloride as a mordant in the acetic acid-ethanol fixative was not useful for the FISH as it affects chromosome structure under our conditions.

Here a new protocol for high-resolution multicolor FISH method is presented which is adapted for mapping banana BAC clones on cell spreads of pachytene complements. We discuss the technical challenges in obtaining good FISH results for two banana varieties as well as the potential application of the technique to other types of cytogenetic works for banana breeding.

\section{Materials and methods}

Plant material

Male flowers of $4 \mathrm{~cm}$ and less were collected from inflorescences of M. acuminata ssp. burmanicoides var. Calcutta 4 (AA) from the Eumusa group (MGIS accession number: NEU0017), and Musa velutina from the Rhodochlamys section (MGIS accession number: NEU0006). We have chosen Calcutta 4 for our study because it is the prime donor species of all banana breeding programs (Swennen and Vuylsteke 1993; Vuylsteke et al. 1993a, b, 1995) and because it is one of the most studied varieties and is a natural candidate for genome sequencing. Also, analyses of Musa diversity using various molecular techniques support the theory that the sections Rhodochlamys (M. velutina) and Eumusa (Calcutta 4) are closely related and provide potential sources of exploitable new genes, thus increasing the gene pool available to banana breeders (Carreel 1994; Jarret and Gawel 1995; Shepherd 1999; Wong et al. 2001-2003). M. velutina was chosen because it possesses genes for drought tolerance, a typical trait of the Rhodochlamys group that can be used for introgression hybridization (Häkkinen 2007). The flowers were collected from the tropical greenhouses at the Catholic University of Leuven, Belgium at 11a.m. and subsequently fixed in ethanol/acetic acid (3:1) fixative for $24 \mathrm{~h}$ and kept until further use in ethanol $70 \%$ at $4^{\circ} \mathrm{C}$.

Selection of anthers, enzyme digestion and slide preparation

All anthers from each flower were screened for pollen mother cells containing meiotic stages. Selection and digestion of anthers were conducted according to Zhong et al. (1996) and Budiman et al. (2004) with some modifications. Briefly, we dissected all five anthers from a fixed flower, and one of them was first stained in lactophenol-acid fuchsin $[0.1 \mathrm{~g}$ acid fuchsin in $50 \mathrm{ml}$ lactophenol (one part of water, one part 
of lactic acid, one part of phenol, two parts of glycerol)] to identify pollen mother cells in pachytene stage. In M. velutina we found pachytene cells in anthers from 7 to $10 \mathrm{~mm}$, while in M. acuminata they were found in anthers of 9-12 mm. All selected anthers were washed with desalted distilled water, rinsed with $10 \mathrm{mmol}^{-1}$ citric buffer $\mathrm{pH} 4.5$ and then treated with an enzyme mixture consisting of $0.1 \%(\mathrm{w} / \mathrm{v})$ pectinase $\mathrm{RS}, 0.1 \%(\mathrm{w} / \mathrm{v})$ cellulase $\mathrm{Y} 23$, and $0.3 \%(\mathrm{w} / \mathrm{v})$ cytohelicase in $10 \mathrm{mmol}^{-1}$ citric buffer, for $<4 \mathrm{~h}$ at $37^{\circ} \mathrm{C}$. Following digestion, the enzyme solution was carefully washed from the tubes and the anthers were dissolved in $100 \mu \mathrm{l} 60 \%$ acetic acid for slides preparation. Digested anthers that were not immediately used were stored in ethanol $70 \%$ at $4^{\circ} \mathrm{C}$.

To prepare chromosome spreads, a $10 \mu \mathrm{l}$ drop of the cell suspension in $60 \%$ acetic acid was placed in the center of a microscopy slide, which had been humidified with water vapor for few seconds (Henegariu et al. 2001). Following, the slide was placed on a hot plate at $55^{\circ} \mathrm{C}$ and just before the drop evaporated completely, a few drops of $60 \%$ acetic acid were placed on the slide ensuring that the large formed drop stayed in the center of the slide. The slide was kept on the hot plate for about $2 \mathrm{~min}$, then washed with ethanol/acetic acid (3:1) fixative, and allowed to dry on the hot plate for few more minutes. The slide was then examined with phase contrast microscopy to assess the quality of the chromosome spreads.

All slides were extra fixed for better preservation of the chromatin during the denaturation and hybridization steps. Two different fixation procedures were tested. In the first one, the slides were submitted to a dehydration step consisting of the immersion of slides in an ethanol series up to $100 \%$ and then in a solution of $2 \%$ formaldehyde. In the second procedure the slides were submitted to a dehydration step as stated above and then were immersed in fresh $100 \%$ ethanol and kept at $-20^{\circ} \mathrm{C}$ overnight, before using them for FISH. To achieve the quality of slides we have obtained in this work we have extensively tested the protocols presented in, at least, 15-20 FISH experiments before adopting them as standards. It is important to stress that variations in the results may occur when different plant material or plant species are used. In our experiments the results were reproducible in more than $95 \%$ of the experiments.
BAC selection and insert purification

Seven BAC clones were selected from two banana BAC libraries held at the Institute of Experimental Botany, Olomouc, Czech Republic (Vilarinhos et al. 2003; Šafár et al. 2004), using as probes ESTs selected from the DATAMusa database (Souza Júnior et al. 2005). The inserts of these BAC clones (MA4_11/ M06, MBP_32N20, MA4_69C10, MA4_48G03, MA4_72/F16 MA4_52E23 and MA4_86B03) were purified according to Woo et al. (1994), with some adaptations. Basically, the BAC containing bacteria were grown in $100 \mathrm{ml} \mathrm{LB}$ medium containing chloramphenicol $\left(25 \mathrm{mg} \mathrm{ml}^{-1}\right)$ at $37^{\circ} \mathrm{C}$ overnight under vigorous shaking. The cells were then spun down (4,000 rpm for $15 \mathrm{~min}$ ) in $50 \mathrm{ml}$ Falcon tubes, and the pellets were re-suspended in STE $\left(1 \mathrm{~mol} \mathrm{l}^{-1} \mathrm{NaCl}\right.$, $1 \mathrm{~mol} 1^{-1}$ Tris- $\mathrm{HCl}$ and $0.5 \mathrm{~mol} 1^{-1}$ EDTA at $4^{\circ} \mathrm{C}$ ). Cells were harvested again by centrifugation (4,000 rpm for $15 \mathrm{~min})$, re-suspended in ALS-I $\left(1 \mathrm{~mol} \mathrm{l}^{-1}\right.$ glucose, $1 \mathrm{~mol} \mathrm{l}^{-1}$ Tris- $\mathrm{HCl}$ and $0.5 \mathrm{~mol} \mathrm{l}^{-1}$ EDTA) supplemented with $0.5 \mathrm{ml}$ lysozyme solution $\left(10 \mathrm{mg} \mathrm{ml}^{-1}\right.$ in $10 \mathrm{mM}$ Tris- $\mathrm{HCl}$, $\mathrm{pH}$ 8) and incubated on ice for $20 \mathrm{~min}$. Following, $10 \mathrm{ml}$ ALS-II (10 mol $\mathrm{l}^{-1} \mathrm{NaOH}$ and $10 \% \mathrm{SDS}$ ) were added and the suspension was mixed and left for few minutes at room temperature (RT). After adding $5 \mathrm{ml}$ ALS-III $\left(3 \mathrm{~mol} \mathrm{l}^{-1}\right.$ potassium acetate and glacial acetic acid), the suspension was mixed and stored on ice, centrifuged $\left(4,000 \mathrm{rpm}\right.$ for $15 \mathrm{~min}$ ) at $4^{\circ} \mathrm{C}$ and then filtered with miracloth (Calbiochem, 475855, IR). A total of 0.6 volume of isopropanol was added to the remaining solution, which was mixed well and allowed to precipitate at room temperature. Nucleic acid was collected by centrifugation $(4,000 \mathrm{rpm}$ for $15 \mathrm{~min}$ ), and then washed with ethanol $70 \%$. After drying, the pellets were transferred to Eppendorf tubes using a pipette tip then they were dissolved in TE ( 1 mol $1^{-1}$ Tris- $\mathrm{HCl}$ and $0.5 \mathrm{~mol} \mathrm{l}^{-1}$ EDTA) supplemented with $1 \mu \mathrm{l}$ RNAse, and the solution was incubated at $37^{\circ} \mathrm{C}$. DNA was extracted with one volume of phenol/chloroform/isoamylalcohol (25:24:1), phases were separated by centrifugation (4,000 rpm for $15 \mathrm{~min})$, extracted again with one volume chloroform/isoamylalcohol (24:1) and, finally, DNA was precipitated with 0.1 volume of $3 \mathrm{~mol} \mathrm{l}^{-1}$ sodium acetate plus 0.6 volume of isopropanol. Pellets were washed with $70 \%$ ethanol, re-suspended in $100 \mu \mathrm{l} \mathrm{TE}$, and stored at $-20^{\circ} \mathrm{C}$ until 
needed. The size of DNA fragments was checked by gel electrophoresis.

\section{Probe DNA labeling}

We used both direct and indirect labeling for the multi-color FISH. As to the direct labeling, the BAC clone inserts were labeled by combining $1 \mu \mathrm{g}$ of probe DNA in $12 \mu \mathrm{l}$ of water, $2 \mu \mathrm{l}$ of nucleotide mix, $2 \mu \mathrm{l}$ of $\mathrm{x}$-dUTP (x being the fluorochromes Cy3 or DEAC) and $4 \mu \mathrm{l}$ of the Nick Translation Mix (Roche diagnostics, Germany). As to the indirect labeling, BAC clones were labeled by combining $16 \mu \mathrm{l}$ of the probe with $4 \mu \mathrm{l}$ of Dig or Biotin bounded to the nick translation mix (Roche diagnostics, Germany). The final labeling mixtures were shaken gently and incubated at $15^{\circ} \mathrm{C}$ for $90 \mathrm{~min}$ for hybridization. After checking the fragment sizes by gel electrophoresis, the reaction was stopped by adding EDTA and heating the probe for $10 \mathrm{~min}$.

\section{Fluorescent in situ hybridization}

For mapping the BAC clones on pachytene chromosomes we adapted the protocol of Budiman et al. (2004). Summarizing, slides were heated to $65^{\circ} \mathrm{C}$, treated with RNAse A at $37^{\circ} \mathrm{C}$, washed with $2 \times$ SSC for $5 \mathrm{~min}$, treated with $0.01 \mathrm{~mol} 1^{-1} \mathrm{HCl}$, followed by pepsin $0.01 \%$, washed with Milli Q water and then with $2 \times$ SSC. The slides were extra fixed with formaldehyde buffer $\left(10 \times\right.$ PBS, $10 \times 500 \mathrm{mmol} \mathrm{l}^{-1}$ $\mathrm{MgCl}_{2}$, and $37 \%$ formaldehyde), washed with $2 \times$ SSC, and dehydrated in an ethanol series up to $100 \%$. A hybridization mix consisting of the labeled probes, hybridization buffer (HB 50) and 20\% dextran sulfate was prepared and $20 \mu \mathrm{l}$ of the mix was placed on the slide, which was baked for no more than $10 \mathrm{~min}$ at $80^{\circ} \mathrm{C}$, before being allowed to hybridize at $37^{\circ} \mathrm{C}$ overnight. After hybridization, the slides were treated with $50 \%$ formamide in $2 \times \mathrm{SSC}$, washed with $4 \mathrm{~T}$ $(4 \times$ SSC and $0.5 \mathrm{ml}$ Tween 20) and then treated with TNB buffer (Tris, $\mathrm{NaCl}, 36 \% \mathrm{HCl}$, Blocking reagent and purified water) at $37^{\circ} \mathrm{C}$. For detection we treated the slides with Avidin Texas Red $(1: 800)$ at $37^{\circ} \mathrm{C}$, washed with $4 \mathrm{~T}$ and then with TNT $(0.05 \%$ Tween 20 in $\mathrm{TN}$ [Tris, $\mathrm{NaCl}$ and $36 \% \mathrm{HCl}$ ]). The slides were treated with Biotinlyed Anti-avidine (1:100) and sheep Anti-dig-FITC $(1: 200)$ at $37^{\circ} \mathrm{C}$, washed with TNT, and then treated with Avidin-Texas Red
(1:800) and Anti-sheep-FITC (1:800) in TNB at $37^{\circ} \mathrm{C}$. Slides were washed with $2 \times \mathrm{SSC}$, dehydrated in an ethanol series, and finally stained with DAPI in Vectashield (1:20).

Image capturing and analysis were conducted according the procedure described by Szinay et al. (2008). Briefly, slides were examined under a Zeiss Axioplan 2 Imaging Photomicroscope equipped with epifluorescence illumination and filter sets for DAPI, DEAC, FITC, Cy3, and Cy3.5 or Texas Red. The images were captured by a Photometrics Sensys $1,305 \times 1,024$ pixel CCD camera and analyzed with the Genus Image Analysis software (Applied Imaging Corporation). DAPI images were displayed in dark to middle gray and sharpened with a Hi-Gauss high pass spatial filter to show up small details and heterochromatin morphology. The other fluorescence images were pseudo-colored in blue (DEAC), green (FITC), orange (Cy3) and red (Cy3.5, Texas Red) and merged in a multichannel mode. Chromosome straightening was done with the straighten-curved-15 objects plugin of ImageJ (Kocsis et al. 1991) and image optimization was conducted for contrast and brightness, inversion to gray scale, cropping or color saturation using Adobe Photoshop software (Adobe Systems Inc., USA).

\section{Results and discussion}

In the experiments presented here $M$. acuminata and $M$. velutina differed considerably in their response to the different steps in the procedures and each had to be adapted for optimal chromosome spreads and FISH. We encountered a series of technical challenges that had to be overcome in order to produce good FISH results with the Musa material. The first challenge was the asynchronous development of microsporocytes in a single anther (Fig. 1a, b). The second challenge was that to obtain good pachytene chromosome spreads a considerable number of male flowers had to be collected and analyzed. The third problem we encountered was the dense cytoplasm of the microsporocytes (Fig. 1c), which produced a high level of background fluorescence phenolic compounds (Fig. 1d). To overcome these challenges we had to adapt the anthers digestion protocol because of the rigid wall of the banana pollen mother cells. We had also to deal with dense nature of the microsporocytes 

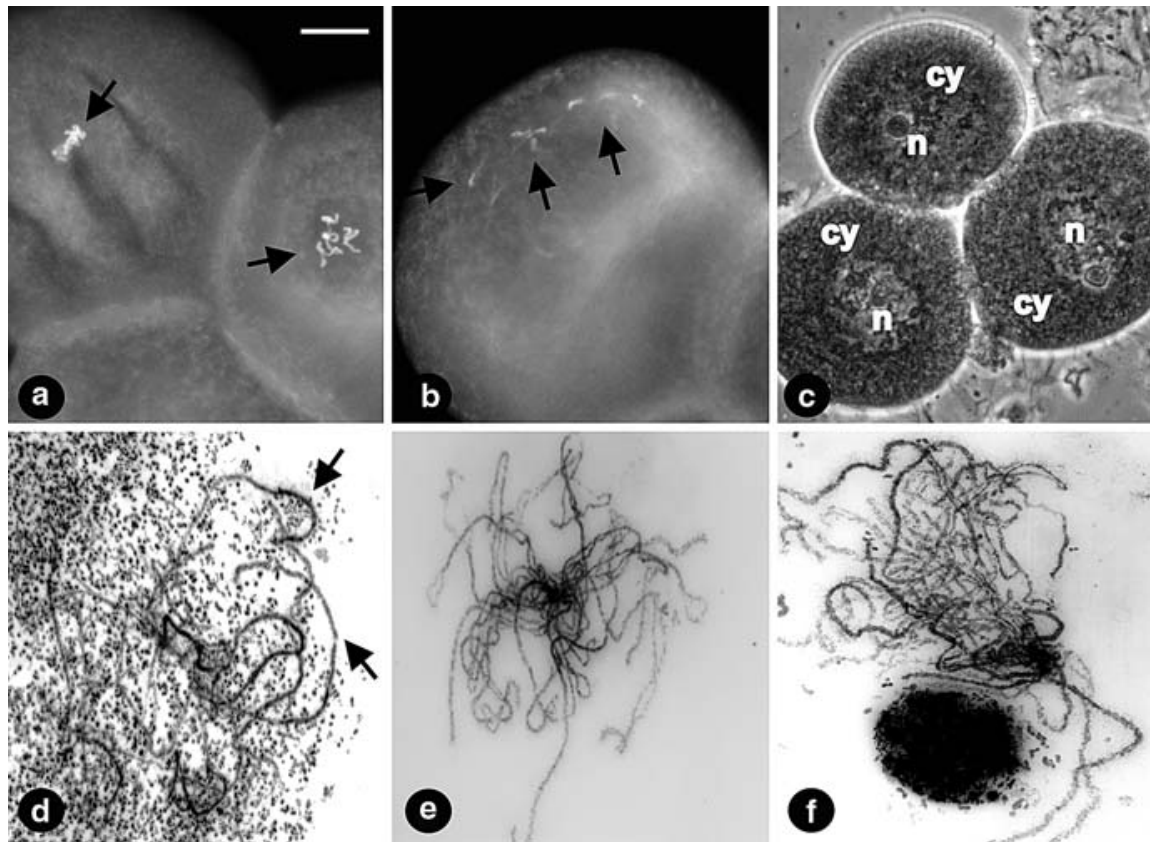

Fig. 1 a DAPI stained microsporocytes of $M$. velutina at metaphase I. b Microsporocytes at pachytene. Note the dense fluorescing cytoplasm in the cells. c Phase contrast photomicrograph of microsporocytes displaying dense granulated cytoplasm (cy). n, nucleus with dense chromatin mass and nucleolus. d Inverted image of DAPI stained pachytene

cytoplasm and the asynchronous development of the microsporocytes, which made difficult the preparation of good chromosome spreads, free of background and with a sufficient number of mother cells at pachytene. Although we sometimes experienced strong background of the cytoplasm in anther cell spreads of other plants including cucumber and tomato, we encountered more serious problems in the banana material due to the large content of starch and polyphenolic compounds.

Our findings also showed that the banana species used differed somewhat in their response to the overall FISH procedure. For instance, it was easier to digest anthers and prepare chromosome spreads from $M$. velutina than from $M$. acuminata. To overcome these differences some adjustments had to be made in the slide preparation protocols. M. acuminata demanded a longer $(3.5 \mathrm{~h})$ enzyme digestion time than $M$. velutina $(3 \mathrm{~h})$. This difference was probably due to the fact that, for the species studied, we found microsporocytes in the pachytene stage in anthers with different sizes. chromosomes (black arrows) of poorly spread microsporocytes surrounded by dense cytoplasm; (e), (f) inverted image of DAPI stained pachytene chromosomes of Musa acuminata and Musa velutina, respectively, free of fluorescing background; $1 \mathrm{~cm}$ bar equals: (a, b) $10.5 \mu \mathrm{m}$; (c) $21 \mu \mathrm{m}$; (d-f) $4.63 \mu \mathrm{m}$

The spreading method used was essentially the same for both species, but the pre-treatment of the slides for the FISH procedure differed substantially. Chromatin preservation was achieved with two different extra fixation steps. This procedure was crucial to guarantee preservation of the chromatin structure during the FISH experiments. For $M$. velutina a formaldehyde fixation for 10-15 min worked better, while $M$. acuminata responded better to the fixation with ethanol $100 \%$ for $24 \mathrm{~h}$ at $-20^{\circ} \mathrm{C}$. This fact was evident after the FISH procedure, when slides of the different species were compared under the microscope (data not shown). Because the extra fixation made the chromatin less accessible for the labeled probes, we had to adjust the time of pepsin treatment as well to relax the DNA structure and guarantee adequate hybridization of the labeled probes. For $M$. velutina a pepsin treatment for 2.5 min worked better, while for $M$. acuminata a pepsin treatment of 3-4 min gave the best results.

After overcoming the challenges good results were obtained. Initially, we set up a pilot experiment for 
testing the FISH conditions where $5 \mathrm{~S}$ and $45 \mathrm{~S}$ ribosomal DNA hybridized against slides with chromosomes spreads of M. velutina. The 5S ribosomal DNA showed fluorescence signals on two chromocenters of an interphase nuclei, while the $45 \mathrm{~S}$ ribosomal DNA labeled with red color (Texas Red) hybridized with four chromocenters and two metaphase chromosomes present in the same slide (data not shown).
In the next series of FISH experiments we tested hybridizations with two BACs (MA4_11/M06 and MBP_32/N20) labeled with two different fluorochromes (Texas Red and FITC). Good signals were detected in the chromosomes of both species, but their chromosomal location was different. For $M$. velutina the signals of the two BACs appeared clearly in two different chromosomes (Fig. 2a-c), but MBP_32/N20 also produced a signal in the same
Fig. 2 FISH mapping of two BAC clones hybridized on pachytene chromosome spreads of $M$. velutina and M. acuminata. BAC clones 11/M06 and 32/N20 hybridized in different chromosomes (a). Note that BAC 11/M06 produced two signals in two unpaired homologues of one chromosome (a, b), while BAC clone $32 / \mathrm{N} 20$ produced multiple signals in different chromosomes (a-c) and in the same chromosome BAC (11/M06) was located (b). This co-localization pattern was identified in distinct chromosomes of different preparations obtained when the experiment was repeated $(\mathbf{b}, \mathbf{d}, \mathbf{e})$. Note also that the signal of BAC 32/ $\mathrm{N} 20$ that is co-localized with BAC 11/M06 (b) seem to be composed of multiple smaller signals as it can be seen by the closely located single dots that become separated when the chromatin structure is less condensed (d, e). Similar co-localization of both BAC clones was also found in $M$. acuminata $(\mathbf{g}, \mathbf{i})$, however, the BAC clones appeared much closer to each other than in M. velutina $(\mathbf{f}, \mathbf{h})$. Bar $(1 \mathrm{~cm})$ equals: (a) 4.63; (b, c) $0.66 \mu \mathrm{m}$; (d, e) $1.26 \mu \mathrm{m}$; (f, g) $4.63 \mu \mathrm{m}$; (h, i) $0.86 \mu \mathrm{m}$
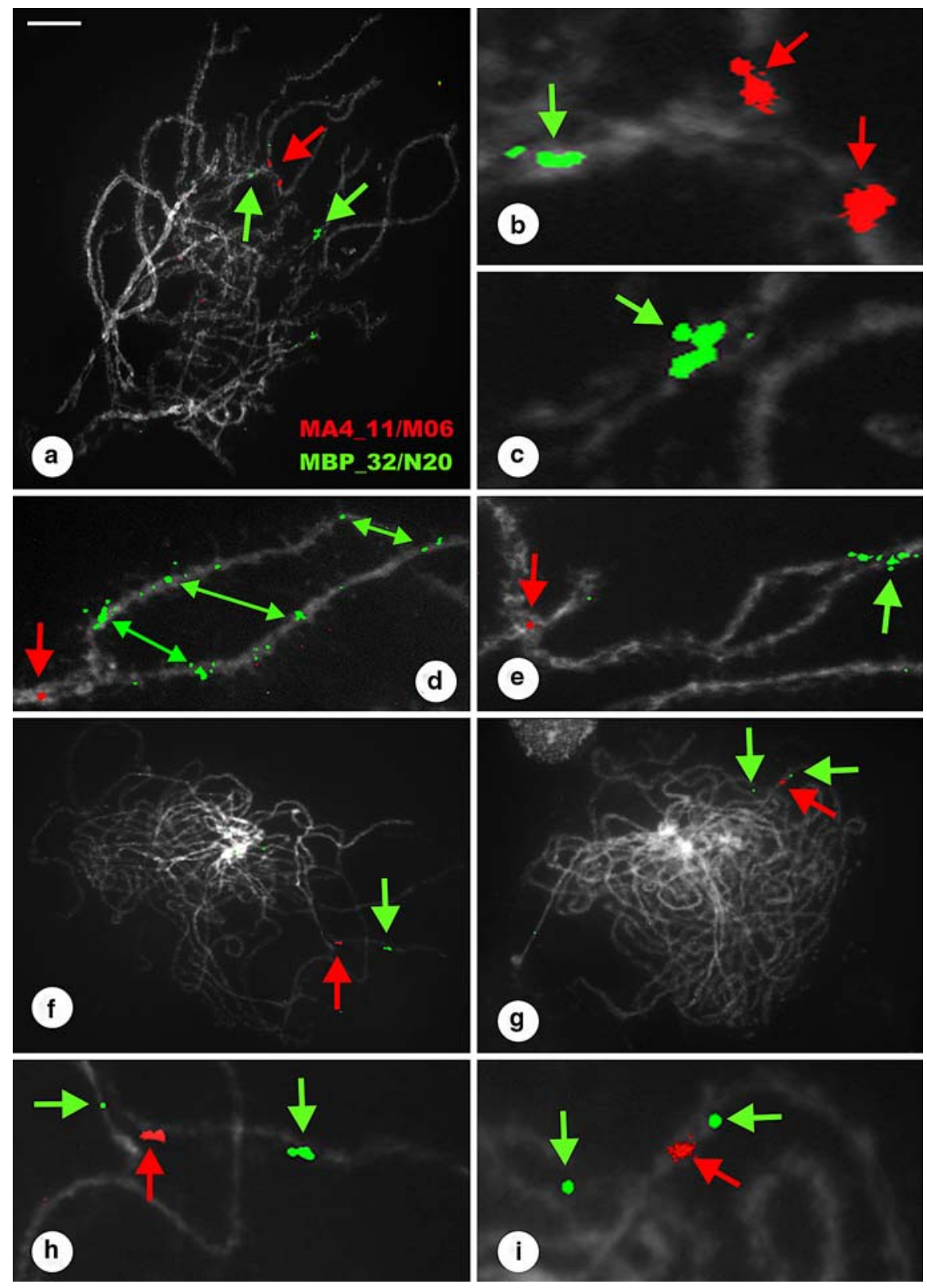
chromosome where the signal of MA4_11/M06 was detected (Fig. 2a, b, d, e). A third signal of BAC 32/ $\mathrm{N} 20$ is also observed in a third chromosome (Fig. 2a), however, since this signal was not consistently observed in repetitions of the experiment we believe that this signal was consequence of either unspecific hybridization or fluorochrome precipitation. BAC MBP_32/N20 seems to occur on multiple foci in the same region of a chromosome as it can be seen in less condensed and unpaired homologues (Fig. 2d). For M. velutina the different BACs also co-localized in the same chromosome (Fig. 2f, h), but they appeared much closer with each other in $M$. acuminata (Fig. 2g, i). In addition, MBP_32/N20 produced multiple signals in different chromosomes in both species (Fig. 2a, g), but MA4_11/M06 showed only one signal in one chromosome. Finally, in a third experiment, we painted four BACs (MA4_48/G03, MA4_69/C10, MA4_72/F16 and MA4_86/B03) simultaneously in the chromosomes of both species. We were able to detect good signals of the BACs every time the experiments were repeated (Fig. 3a, e). For $M$. acuminata, BACs MA4_48/G03, MA4_69/C10 and MA4_86/B03 did produce signals in three distinct chromosomes (Fig. 3c, d). Note that the three BACs produced signals that appeared also in an interphase nucleus present side by side with a pachytene complement (Fig. 3a, b). The same pattern of signals was found in pachytene when the experiment was repeated (data not shown). However, no signal was detected for MA4_72/F16. Similar results were found for $M$. velutina in the first time the experiment was conducted. Unlike $M$. acuminata, multiple signals of the MA4_48/G03, MA4_69/C10 and MA4_86/ B03 were detected, sometimes even in the same chromosome (Fig. 3e). These painted chromosomes were straightened to facilitate the comparison of the BACs positions (lower part of Fig. 3e). Observing the chromosomes it becomes clear that certain BACs (MA4_86/B03 and MA4_48/G03) produced signals at some distance from each other (Fig. 3: 1 and 5), while MA4_69/C10 produced two signals very close to each other (Fig. 3: 4). In subsequent repetitions of the experiments we substituted BAC MA4_72/F16 by the BAC MA4_52E23. As the results show, we were able to physically locate all four BACs on four different chromosomes of M. acuminata (Fig. 4a) and M. velutina (data not shown).
Our results showed that some of the studied BAC clones produced only single signals, while others produced multiple signals, which appeared in only one chromosome or, in some cases, in different ones. In this study the different position of BACs MA4_11/ M06 and MBP_32/N20 among the studied species indicates that during evolution an inversion or translocation may have occurred in that region. These types of rearrangements are discussed in the work by Shepherd (1999), who presents a detailed description of inversions, translocations and anaphase bridges that occur in different cultivars and hybrids of M. acuminata.

Another interesting result we found in the work was the fact that we detected multiple signals for some of the BACs in both species. The BAC clones we have used in this research work were selected because they contain DNA sequences with homology to resistance genes. Resistance genes share some degree of homology of some conserved motifs, which are the NBS (nucleotide binding site) and LRR (leucine rich repeat) domains (Miller et al. 2008). Depending on the degree of homology of these conserved domains between, for example, BAC MBP_32/N20 and other DNA sequences throughout the genome, multiple signals could be detected. Miller et al. (2008) reported that a resistance gene analog (MaRGA08), which corresponds to BAC MBP_32/N20, was identified as single copy in the genome of $M$. acuminata Calcutta 4, but as multiple copies in Grande Naine and PKW. The fact that this BAC does appear as multiple copies in the M. velutina genome suggests that it is possible that it may share a higher degree of homology to these species than to M. acuminata. This type of confirmation can be easily achieved by means of high-resolution FISH.

One should be aware that unspecific hybridization may occur mostly if the BAC contains high content of repetitive sequences. However, this was not the case for the BACs studied in this work, as the signals detected were clearly true signals located in areas distant from heterochromatin regions. This is the reason why we had no need to use blocking DNA in the hybridization mix.

Our results led us to the conclusion that no single protocol can be used for setting up FISH protocols for all diploid bananas. Changes in protocols for digestion of microsporocytes with pectolytic enzymes, spreading preparation and FISH procedure will be 

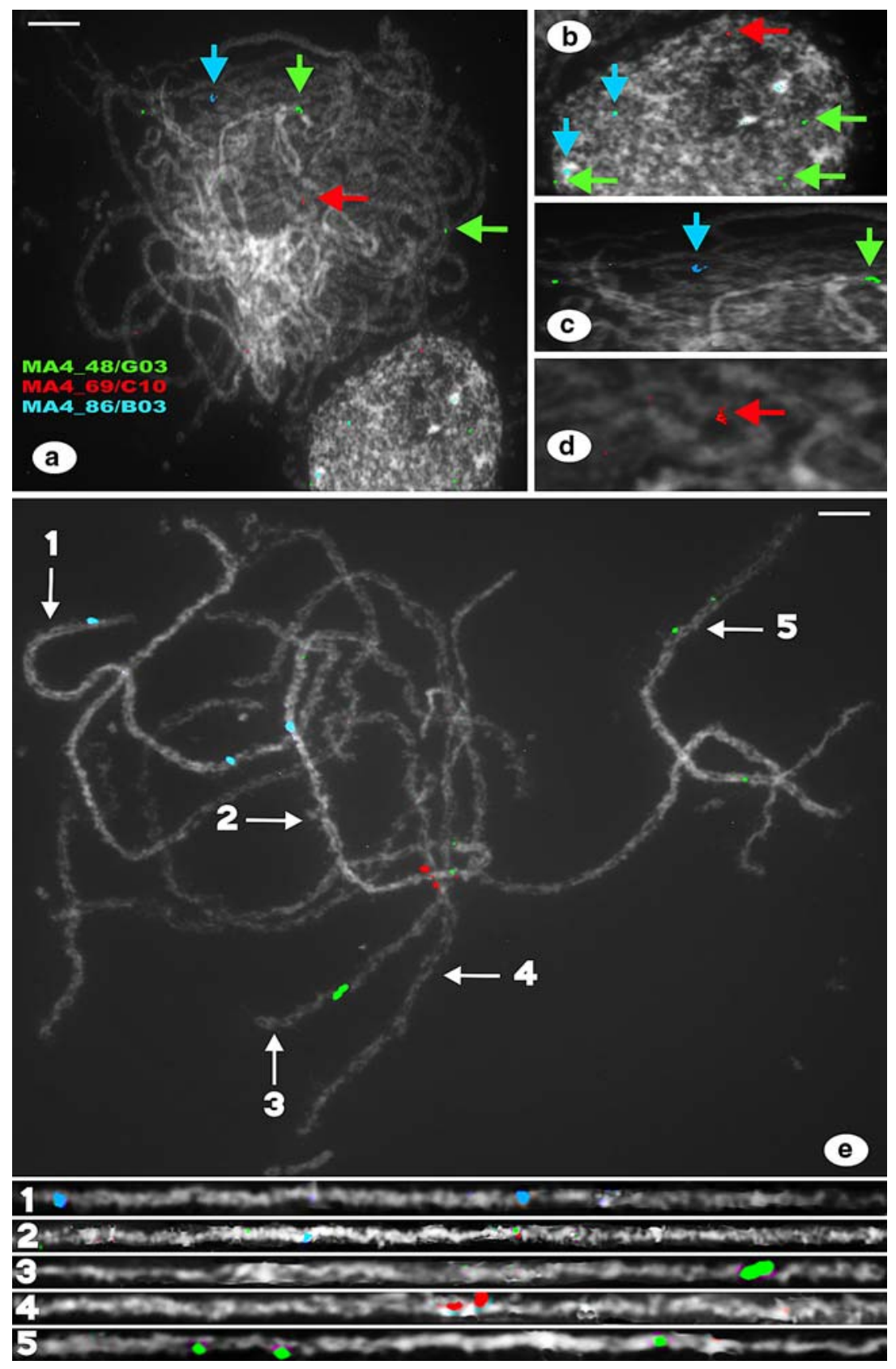

Fig. 3 FISH mapping of BAC clones 48/G03 (green), 69/C10 (red) and 86/B03 (blue) hybridized against chromosomes of $M$. acuminata and $M$. velutina. a General view of a pachytene complement and an interphase nucleus displaying signals of the three BACs (colored arrows). Note that, in M. acuminata, BACs $(69 / \mathrm{C} 10)$ and (86/B03) produced just one signal in the pachytene complement, while BAC (48/G03) produced more than one signal and in different chromosomes (b-d). In the interphase nucleus, as expected, each of the BACs that produced single signals generated two signals by hybridizing with two different chromocenters, while BAC 48/G03 produced multiple signals (b). e FISH mapping of BAC clones 48/G03 (green), 69/C10 (red), 86/B03 (blue) in M. velutina. The labeled BACs hybridized in different chromosomes (1-5) and, in some cases, in different locations of the same chromosome. The five chromosomes that hybridized to a BAC were stretched to facilitate the localization of the BACs in each chromosome (lower part of Fig. 4). The stretching of the chromosomes is very useful for comparing cytogenetic maps with linkage group or genetic maps. Bar $(1 \mathrm{~cm})$ equals: (a) $3.47 \mu \mathrm{m}$; (b, c) $0.86 \mu \mathrm{m}$; (d) $0.57 \mu \mathrm{m}$; (e) $3.47 \mu \mathrm{m}$ 
Fig. 4 FISH mapping of BAC clones 48/G03 (green), 69/C10 (red), 86/ B03 (blue) and 53/E23 (yellow) hybridized against chromosomes of $M$. acuminata. a General view of a pachytene complement displaying signals of the four BACs in four different chromosomes. Details of each BAC can be seen in (b-e). Bar $(1 \mathrm{~cm})$ equals: (a) $4.63 \mu \mathrm{m}$; (b-e) $0.86 \mu \mathrm{m}$

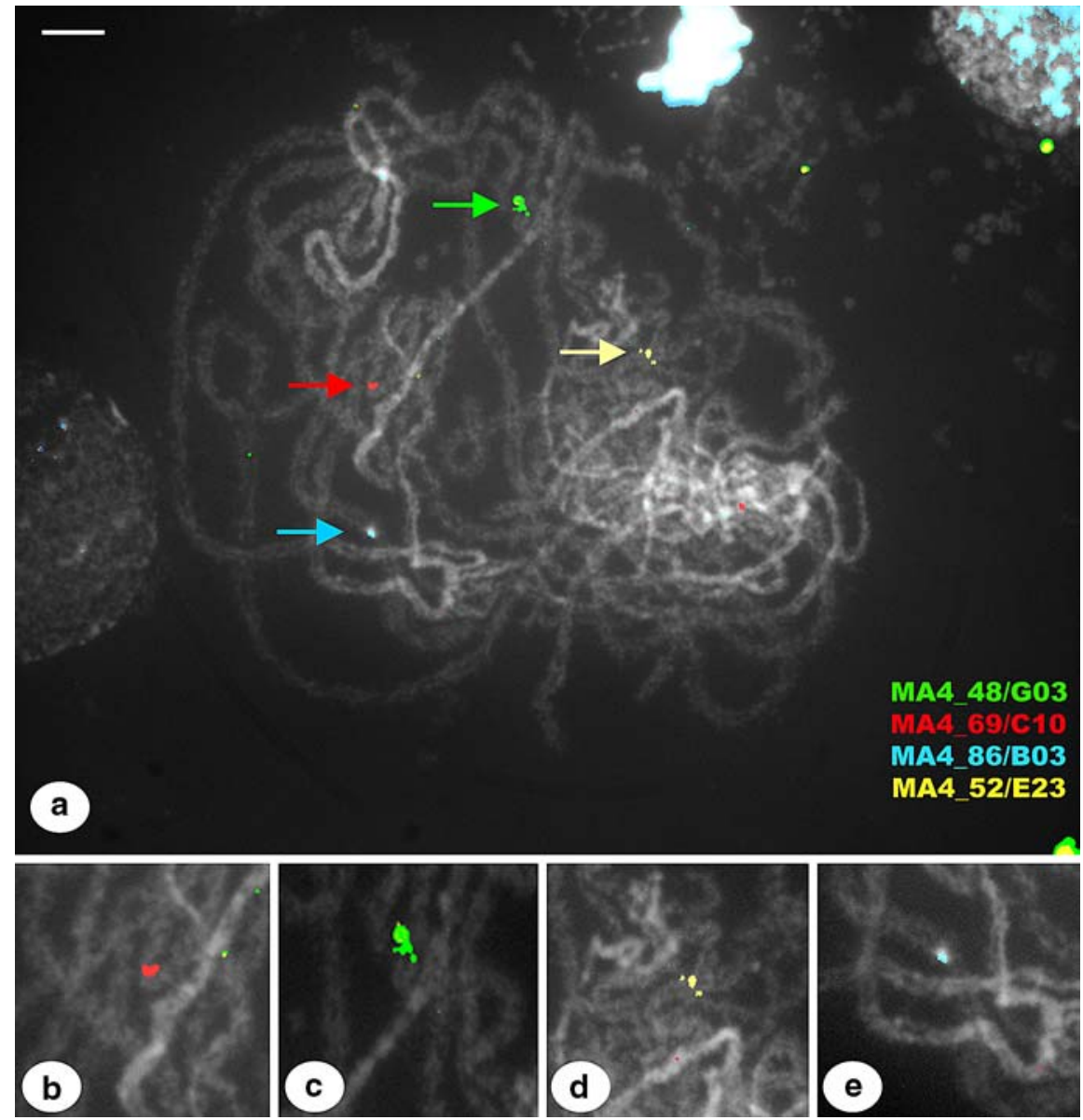

MA4 48/G03

MA4 86/B03 MA4 52/E23 always necessary to produce reliable results. Henegariu et al. (2001) pointed out the importance of each step of the overall FISH procedure. According to these authors among the most important steps to obtain reliable results are the slide preparation with chromosome spreads and the pre-treatment of the slides for the FISH procedure. Difference in these steps may be the reason why high-resolution FISH protocols are frequently different for different species (Koumbaris and Bass 2003; Budiman et al. 2004; Ina et al. 2007).

In bananas, up to now, no work was conducted to explore the potential of the technique in unveiling genome complexity and structure, probably due to the difficulties that arise during the overall FISH procedure. What makes this technique a powerful one is the fact that it relies on pachytene complements rather than mitotic chromosomes. By our estimations banana pachytene chromosomes are about 15 times longer than metaphase chromosomes (data not shown).
This is the first report presenting the results of an elegant high-resolution FISH method used to physically map, simultaneously, BAC clones in two banana species. The results presented in this article indicate that, in bananas, as for other species the use of pachytene chromosomes may provide a degree of precision and resolution that cannot be achieved with FISH procedures conducted with mitotic cells (de Jong et al. 1999). Therefore, with this kind of work, it is possible to determine with high precision the position of BAC clones in specific chromosomes of the Musa genome. This precision in positioning of BACs can be very useful for studies in which the objective is to generate a detailed cytogenetic map, which are very useful for validating the position of markers used for generating genetic maps as it has been done for some crops (Kulikova et al. 2001). Additionally, with this technique it is possible to find small chromosome inversions or deletions, which can provide useful information for phylogenetic studies 


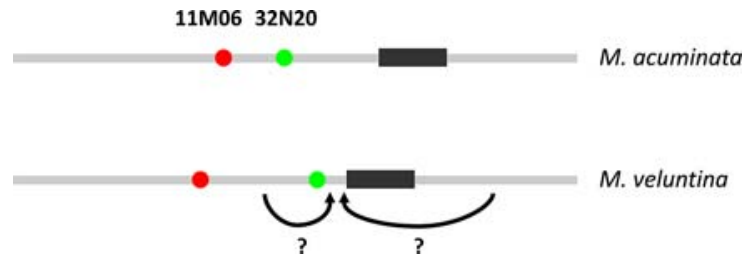

Fig. 5 Schematic representation of high-resolution FISH for establishing chromosomal collinearity and identifying chromosomal arrangements between different genotypes or related species. BACs $11 \mathrm{M} 06$ and $32 \mathrm{~N} 20$ close together in M. acuminata and more distant on the homeologous $M$. velutina chromosome. The arrows with question marks indicate examples of the inversions that give rise to the shift of BAC positions and centromere, but FISH with series of BACs covering full contigs are needed to reveal more precisely the nature and length of the rearrangement

(Lysák et al. 2006). This technique is also instrumental for validating collinearity between potential crossing (Fig. 5) and is helpful in future mapping initiatives, therefore, being very useful for helping assisted breeding programs as well as plant transformation studies, which aim at the development of high quality and more stress adapted bananas cultivars.

Acknowledgments This project was performed in the framework of the MusaForever strategic alliance between Embrapa, the National Agricultural Research Organization of Brazil, and Wageningen University and Research Center, The Netherland. This initiative is financially supported by the Dutch Dioraphte Foundation and the competitive funding system of "macroprogramas" of Embrapa.

Open Access This article is distributed under the terms of the Creative Commons Attribution Noncommercial License which permits any noncommercial use, distribution, and reproduction in any medium, provided the original author(s) and source are credited.

\section{References}

Adeleke MTV, Pillay M, Okali BE (2002) An improved method for examining meiotic chromosomes in Musa L. Hortiscience 37:959-961

Aert R, Sági L, Volckaert G (2004) Gene content and density in banana (Musa acuminata) as revealed by genomic sequencing of BAC clones. Theor Appl Genet 109:129139. doi:10.1007/s00122-004-1603-2

Bartoš J, Alkhimova O, Doleželová M, De Langheb E, Doležel J (2005) Nuclear genome size and genomic distribution of ribosomal DNA in Musa and Ensete (Musaceae): taxonomic implications. Cytog Gen Res 109:50-57. doi: $10.1159 / 000082381$
Budiman MA, Chang SB, Lee S, Yang TJ, Zhang HB, de Jong $\mathrm{H}$, Wing RA (2004) Localization of jointless-2 gene in the centromeric region of tomato chromosome 12 based on high resolution genetic and physical mapping. Theor Appl Genet 108:190-196. doi:10.1007/s00122-003-1429-3

Buhariwalla HK, Jarret RL, Jayashree B, Crouch JH, Ortiz R (2005) Isolation and characterization of microsatellite markers from Musa balbisiana. Mol Ecol Notes 5:327330. doi:10.1111/j.1471-8286.2005.00916.x

Carreel F (1994) Etude de la diversité des bananiers (genre Musa) à l'aide des marqueurs RFLP. PhD thesis, l'Institut National Agronomique Paris-Grignon, France

Cheesman EE (1948) Classification of the bananas II. The genus Musa L. Kew Bull 2:106-117. doi:10.2307/4109207

D'Hont A (2005) Unraveling the genome structure of polyploids using FISH and GISH; examples of sugarcane and banana. Cytog Gen Res 109:27-33. doi:10.1159/000 082378

D'Hont A, Paget-Goy A, Escoute J, Carreel F (2000) The interspecific genome structure of cultivated banana, Musa spp. revealed by genomic DNA in situ hybridization. Theor Appl Genet 100:177-183. doi:10.1007/s00122 0050024

de Jong JH, Fransz P, Zabel P (1999) High resolution FISH in plants-techniques and applications. Trends Plant Sci 4:258-263. doi:10.1016/S1360-1385(99)01436-3

Doležel J, Doleželova M, Novák FJ (1994) Flow cytometric estimation of nuclear DNA amount in diploid bananas (Musa acuminate and Musa balbisiana). Biol Plant 36:351-357. doi:10.1007/BF02920930

Doležel J, Lysák MA, Van den Houwe I, Dolezelová M, Roux $\mathrm{N}$ (1997) Use of flow cytometry for rapid ploidy determination in Musa. Infomusa 6:6-9

Doleželova M, Valárik M, Swennen R, Horry JP, Dolezel J (1998) Physical mapping of the 18S-25S and 5S ribosomal RNA genes in diploid bananas. Biol Plant 41:497505. doi:10.1023/A:1001880030275

Fauré S, Noyer JL, Horry JP, Bakry F, Lanaud C, González de León D (1993) A molecular marker-based linkage map of diploid bananas (Musa acuminata). Theor Appl Genet 87:517-526. doi:10.1007/BF00215098

Food and Agriculture Organization (2004) Overview of world banana production and trade. http://www.fao.org/ docrep/007/y5102e/y5102e04.htm\#bm04.1. Accessed 16 Apr 2008

Häkkinen M (2007) Ornamental bananas: focus on Rhodochlamys. Chron Horticult 47:7-12

Henegariu O, Heerema NA, Wright LL, Bray-Ward P, Ward DC, Vance GH (2001) Improvements in cytogenetic slide preparation: controlled chromosome spreading, chemical aging and gradual denaturing. Cytometry 43:101-109. doi:10.1002/1097-0320(20010201)43:2<101::AID-CYTO $1024>3.0 . \mathrm{CO} ; 2-8$

Heslop-Harrison JS, Scharzacher T (2007) Domestication, genomics and the future for banana. Ann Bot (Lond) 100:1073-1084. doi:10.1093/aob/mcm191

Ina F, Amarillo E, Bass HW (2007) A transgenomic cytogenetics Sorghum (Sorghum propinquum) bacterial artificial chromosome fluorescence in situ hybridization map of maize (Zea mays L.) pachytene chromosome 9, evidence for regions of genome hyperexpansion. 
Genetics 177:1509-1526. doi:10.1534/genetics.107.080 846

Jarret RL, Gawel N (1995) Molecular markers, genetic diversity and systematics in Musa. In: Gowen S (ed) Bananas and plantains. Chapman \& Hall, UK, pp 67-83

Kamaté K, Brown S, Durand P, Bureau JM, De Nay D, Trinh TH (2001) Nuclear DNA content and base composition in 28 taxa of Musa. Genome 44:622-627. doi:10.1139/gen-44-4-622

Kocsis E, Trus BL, Steer CJ, Bisher ME, Steven AC (1991) Image averaging of flexible fibrous macromolecules: the clathrin triskelion has an elastic proximal segment. J Struct Biol 107:6-14. doi:10.1016/1047-8477(91)90025-R

Koumbaris GL, Bass HW (2003) A new single-locus cytogenetic mapping system for maize (Zea mays L.): overcoming FISH detection limits with marker-selected sorghum (S. propinquum L.) BAC clones. Plant J 35:647659. doi:10.1046/j.1365-313X.2003.01829.x

Kulikova O, Gualtieri G, Geurts R, Kim DJ, Cook D, Huguet T, de Jong JH, Fransz PF, Bisseling T (2001) Integration of the FISH pachytene and genetic maps of Medicago truncatula. Plant J 27:49-58. doi:10.1046/j.1365-313x. 2001.01057.x

Lysák MA, Doleželová M, Horry JP, Swennen R, Doležel J (1999) Flow cytometric analysis of nuclear DNA content in Musa. Theor Appl Genet 98:344-1350

Lysák MA, Berr A, Pecinka A, Schmidt R, McBreen K, Schubert I (2006) Mechanisms of chromosome number reduction in Arabidopsis thaliana and related Brassicaceae species. Proc Natl Acad Sci USA 103:5224-5229. doi:10.1073/pnas.0510791103

Miller RNG, Bertioli DJ, Baurens FC, Santos CMR, Alves PC, Martins NF, Togawa RC, Souza Junior MT, Pappas Junior GJ (2008) Analysis of non-TIR NBS-LRR resistance gene analogs in Musa acuminata Colla: isolation, RFLP marker development, and physical mapping. BMC Plant Biol 8:115. doi:10.1186/1471-2229-8-15

Ohl TJ, Cullis MA, Kunert K, Engelborghs I, Swennen R, Cullis CA (2007) Genomic changes associated with somaclonal variation in banana (Musa spp.). Physiol Plant 129:766-774. doi:10.1111/j.1399-3054.2007.00858.x

Osuji JO, Harrison G, Crouch J, Heslop-Harrison JS (1997) Identification of the genomic constitution of Musa L. lines (bananas, plantains and hybrids) using molecular cytogenetics. Ann Bot (Lond) 80:787-793. doi:10.1006/anbo. 1997.0516

Pillay M, Tenkouano A, Ude G, Ortiz R (2004) Molecular characterization of genomes in Musa and its applications. In: Jain SM, Swennen R (eds) Banana improvement: cellular, molecular biology, and induced mutations. Science, Mosco. http://www.fao.org/docrep/007/ae216e/ae 216e0p.htm. Accessed 05 Mar 2008

Ruangsuttapha S, Eimert K, Schröder MB, Silayoi B, Denduangboripant J, Kanchanapoom K (2007) Molecular phylogeny of banana cultivars from Thailand based on HAT-RAPD markers. Genet Resour Crop Evol 54:15651572. doi:10.1007/s10722-006-9169-2

Šafáŕ J, Noa-Carrazana JC, Vrána J, Bartoš J, Alkhimova O, Sabau X, Šimková H, Lheureux F, Caruana ML, Doležel J, Piffanelli P (2004) Creation of a BAC resource to study the structure and evolution of the banana (Musa balbisiana). Genome 47:182-1191
Santos CMR, Martins NF, Hörberg HM, Almeida ERP, Coelho MCF, Togawa RC, Silva FR, Caetano AR, Miller RNG, Souza MT Jr (2005) Analysis of expressed sequence tags from Musa acuminate ssp. Burmannicoides, var. Calcutta 4 (AA) leaves submitted to temperature stresses. Theor Appl Genet 110:1517-1522. doi:10.1007/s00122-005-1989-5

Sharrock S (1989) Collecting Musa in Papua New Guinea. In: Jarret R (ed) Identification of genetic diversity in the genus Musa. INIBAP, Los Banos, pp 140-157

Shepherd K (1999) Cytogenetics of the genus Musa. http:// www.bioversityinternational.org/publications/pubfile.asp? ID_PUB=383. Accessed 10 Mar 2008

Simmonds NW, Shepherd K (1955) The taxonomy and origins of the cultivated bananas. Bot J Linn Soc 55:271-332. doi:10.1111/j.1095-8339.1955.tb00015.x

Souza Júnior MT, Santos CMR, Martins NF, Silva FR, Togawa RC, Cassiano LP, Almeida ERP, Coelho MCF, Caetano AR, Ciampi AY, Mota M, Piffanelli P, Miller RNG (2005) DATAMusa banco de dados de genômica de Musa spp. Bol Pesq Desenv Embrapa 107:1-22

Swangpol S, Volkaert H, Sotto RC, Seelanan T (2007) Utility of selected non-coding chloroplast DNA sequences for lineage assessment of Musa interspecific hybrids. J Biochem Mol Biol 40:577-587

Swennen R, Vuylsteke D (1993) Breeding black sigatoka resistant plantains with a wild banana. Trop Agric 70:74-77

Szinay D, Chang CB Khrustaleva1 L, Peters S, Schijlen E, Stiekema W, van Ham RCHJ, de Jong H, Lankhorst RK (2008) High-resolution chromosome mapping of BACs using multi-colour FISH and pooled-BAC FISH as a backbone for sequencing tomato chromosome 6. Plant $\mathrm{J}$. doi:10.1111/j.1365-313X.2008.03626.x

Tezenas Du Montcel H (1989) M. acuminata subspecies banksii. In: Jarret R (ed) Identification of genetic diversity in the genus Musa. INIBAP, Los Banos, pp 211-218

Thomas-Hall S, Campbell PR, Carlens K, Kawanishi E, Swennen R, Sági L, Schenk PM (2007) Phylogenetic and molecular analysis of the ribulose-1,5-bisphosphate carboxylase small subunit gene family in banana. J Exp Bot 58:2685-2697. doi:10.1093/jxb/erm129

Vilarinhos AD, Piffanelli P, Lagoda P, Thibivilliers S, Sabau X, Carreel F, D'Hont A (2003) Construction and characterization of a bacterial artificial chromosome library of banana (Musa acuminata Colla). Theor Appl Genet 106:1102-1106

Vuylsteke D, Swennen R, Ortiz R (1993a) Registration of 14 improved tropical Musa plantain hybrids with black sigatoka resistance. HortScience 28:957-959

Vuylsteke D, Swennen R, Ortiz R (1993b) Development and performance of black sigatoka-resistant tetraploid hybrids of plantain (Musa spp., AAB group). Euphytica 65:33-42. doi:10.1007/BF00022197

Vuylsteke D, Ortiz R, Ferris S, Swennen R (1995) 'PITA-9': a black-sigatoka-resistant triploid hybrid from the 'false horn' plantain gene pool. HortScience 30:395-397

Wong C, Kiew R, Lamb A, Ohn S, Lee S, Gan L, Gan Y (2001) Placement of three Bornean species of Musa (Musaceae) based on amplified fragment length polymorphism (AFLP). Gard Bull Singap 53:327-341

Wong C, Kiew R, Argent G, Set O, Lee SK, Gan YY (2002) Assessment of the validity of the section in Musa 
(Musaceae) using AFLP. Ann Bot (Lond) 90:231-238. doi:10.1093/aob/mcf170

Wong C, Argent G, Kiew R, Ohn S, Gan Y (2003) The genetic relations of Musa species from Mount Jaya, New Guinea, and a reappraisal of the sections Musa (Musaceae). Gard Bull Singap 55:97-111

Woo SS, Jiang J, Gill BS, Paterson AH, Wing RA (1994)

Construction and characterization of a bacteria artificial chromosome library of Sorghum bicolor. Nucleic Acids Res 22:4922-4931. doi:10.1093/nar/22.23.4922

Zhong XB, de Jong H, Zabel P (1996) Preparation of tomato meiotic pachytene and mitotic metaphase chromosomes suitable for fluorescence in situ hybridization (FISH). Chromosome Res 4:24-28. doi:10.1007/BF02254940 